\title{
A docência como experiência ética: aproximações entre os estudos foucaultianos e a prática docente $^{1}$
}

\author{
André Marcio Picanço Favacho²
}

\begin{abstract}
Resumo
Este artigo busca pensar a experiência docente contemporânea à luz dos aportes teórico-metodológicos foucaultianos da ética. Pretende discutir, a partir de projetos de docentes brasileiros submetidos a uma premiação nacional, os enunciados éticos que esses sujeitos foram capazes de produzir tanto como manifestação de ética quanto de política. Para isso, discute as noções de ética e de experiência na obra de Michel Foucault; em seguida caracteriza os aspectos mais relevantes da pesquisa realizada sobre os projetos de professores premiados nacionalmente; por fim, ensaia uma possível atividade ética dos professores. A conclusão não poderia ser outra: numa perspectiva ética, os professores experimentam, por si mesmos - em relação aos outros, obviamente -, a construção de sentidos para uma docência atual - passível de críticas, certamente, mas devidamente situada -, capaz de produzir clivagens, acordos, divisas e modos de existir no interior mesmo de uma docência específica, ou seja, global, local, humanista e de resolução de problemas sociais.

Palavras-chave: Foucault; Ética; Experiência; Docência; Premiações.
\end{abstract}

L'enseignement en tant qu'expérience éthique: les approches entre les éstudes foucaultians et la pratiqueen enseignante

\section{Résumé}

L'article cité essaie penser à l'expérience d'enseignement contemporaine sur les apports théoriques et méthodologiques foucaultians de l'éthique. Il prétends discuter, a partir des projets d'enseignants brésiliens soumis à un prix national, les énoncés éthiques que tels personnes étaient capables de produire, autant que manifestation éthique comme politique. Pour cela, il discute la notion d'éthique et l'expérience dans l'œvre de Michel Foucault; ensuite, il définit les aspects les plus pertinents de la recherche achevée; pour conclure, il teste une possible activité éthique des professeurs. La conclusion ne peut être pas autre: dans une approche éthique, les professuers ont éprouvé, eux-mêmes, en relation aux autres - évidemment - la construction des sens pour l'enseignement actuel. Un enseignement susceptible aux critiques, certainement, mais correctement situé, capable de produir des clivages, des accords, des frontières et des raisons d'être dans l'intérieur d'un enseignement spécifique, c'est-à-dire, global, local, humaniste et de résolution des problèmes sociales.

Mots-clés: Foucault; Éthique; Expérience; Enseignement; Prix.

\section{Introdução}

A experiência docente tem sido investigada sob várias possibilidades, entre as quais destaco, sobretudo a partir dos anos 1980, quatro direções: para uns, ela é um conjunto de

\footnotetext{
${ }^{1}$ Estudo realizado com o apoio da Fundação de Amparo à Pesquisa de Minas Gerais - FAPEMIG e do Conselho Nacional de Desenvolvimento Científico e Tecnológico - CNPq, por meio do Edital Universal 2014.

2 Faculdade de Educação da Universidade Federal de Minas Gerais (UFMG), Belo Horizonte, amfavacho@hotmail.com.
}

Periódico Horizontes - USF - Itatiba, SP - Brasil - e019024 
saberes $^{3}$; para outros, ela só se mostra por meio da memória e de narrativas docentes ${ }^{4}$; outros se ocupam com a relação experiência e subjetividades dos/as professores/as ${ }^{5}$; outros, ainda, acreditam que ela diz respeito aos atos de criação e/ou invenção dos/as professores/as em seus cotidianos $^{6}$. Porém, um campo não se encontra ainda devidamente explorado: a experiência docente como experiência ética. Insisto nessa discussão porque, primeiro, em matéria de educação, a ética sempre foi um assunto secundário e, quando tratada, foi sucessivamente tomada como moral, isto é, como valores ${ }^{7}$. Porém, mais do que isso, insisto nessa discussão porque me parece bastante pertinente ou potente experimentar, nas pesquisas, um tipo específico de ética: a ética foucaultiana.

A ética, nessa perspectiva, é a relação do sujeito consigo mesmo a fim de governar a si e o outro. Foucault pensou tal ética nos estudos sobre a sexualidade e sobre o cristianismo, nos quais mostrou ser possível separar e relacionar o código moral, a moralidade dos comportamentos e a ética. Enquanto o primeiro é a submissão a um código de conduta e o segundo, uma variação da prática do sujeito em relação ao código, o terceiro (a ética) é "a maneira pela qual se deve constituir a si mesmo como sujeito moral" (FOUCAULT, 2003a, p.27).

Em Foucault, esses diferentes níveis de abordagem da relação do sujeito com o outro tem a maior importância, pois seu interesse era pensar a singularidade do sujeito diante dos códigos morais, isto é, diante de um código, há várias maneiras de pô-lo em prática. Assim, não se trataria apenas de submissão, de variação de comportamentos, mas também da relação do sujeito com determinados códigos.

A finalidade deste artigo é especular, a partir de um recorte preciso de pesquisa, qual é ou pode ser a relação dos/as professores/as consigo mesmo/os na experiência docente; saber quais os elementos morais eles/as dispõem para realizar sua docência; como eles/as os colocam em prática e com que finalidade. Para isso fará, em primeiro lugar, uma breve contextualização do estudo, a fim de mostrar o recorte feito para atender a isso que chamo de ética docente. Em seguida, discutirá as noções de ética e de experiência em Michel Foucault. Por fim, descreverá

\footnotetext{
${ }^{3}$ Tardif (2002); Larrosa (2002); Lüdke (2001); Monteiro (2001).

4 Josso (2004).

${ }^{5}$ Paquay et al. (2001).

${ }^{6}$ Larrosa (2017); Martins, Netto, Kohan (2014).

${ }^{7}$ Menin (2002); Oliveira (2001).
}

Periódico Horizontes - USF - Itatiba, SP - Brasil - e019024 
uma possível analítica das práticas docentes, destacando certos elementos de uma ética docente.

\section{Sobre a contextualização da pesquisa}

Estando a ética foucaultiana localizada na junção entre singularidades e práticas históricas, entre o si e o outro, entre os limites e suas ultrapassagens, entre a crítica e as formas de governo impostas, a tarefa da pesquisa foi encontrar uma atividade docente que representasse bem essa situação, digamos, limítrofe entre liberdades e urgências políticas. A ideia era encontrar uma prática na qual o/a professor/a gozasse da maior liberdade possível para exercer sua docência. A aposta era de que nela residiria um tanto mais de desejo e autonomia docente diante das formas de governo. Obviamente, eu poderia escolher uma atividade qualquer de um professor ou professora, afinal não se trata, de maneira alguma, de uma ética livre de interferências externas. Mas, a fim de fugir das análises que recaem sobre "as condições do trabalho docente" (embora reconheça sua importância), quis localizar uma prática em que o/a professor/a não estivesse externamente obrigado/a a fazer.

Com um pouco de atenção, logo percebi que, na atualidade, há uma espécie de dispositivo de premiação a professores, alunos e gestores circulando mundo afora ${ }^{8}$. São prêmios, concursos, competições nacionais, estaduais, municipais, internacionais, públicas, privadas, em parcerias ou não. Há prêmios em dinheiro (alguns milionários) ${ }^{9}$, prêmios em medalhas (no caso das olimpíadas) e outros que combinam premiação em dinheiro com viagens, formação e equipamentos para as escolas nas quais os/as professores/as trabalham. Essas premiações se multiplicam: Itaú Social e Unicef; Professores do Brasil/MEC; Educador Nota 10/Fundação Victor Civita; Respostas para o Amanhã/Samsung/CENPEC; Desafio Diário de Inovações/PORVIR/IBFE (Instituto Brasileiro de Formação de Educadores); Criativos da Escola/Instituto Alana; Viva Leitura/MEC/OEI; Educadores Especialistas da América Latina/Microsoft; Global Teacher Prize

\footnotetext{
${ }^{8}$ As premiações para docentes acontecem desde as primeiras décadas do século XX, sob o nome de "concurso". Sobre essa discussão, consultar BICCAS, M. S. (2005).

${ }^{9}$ Segundo o site do MEC, em 2017, a Varkey Foundation, da Inglaterra, pagou um prêmio de US\$ 1 milhão. Disponível em: http://portal.mec.gov.br/component/tags/tag/41791-global-teacher-prize. Acesso em: 05 dez. 2017.
}

Periódico Horizontes - USF - Itatiba, SP - Brasil - e019024 
(Nobel da Educação); Professor Rubens Murillo Marques/Fundação Carlos Chagas.

Apesar da evidente proliferação dessas premiações, não é correto equipará-las. É necessário levar isso muito a sério, porque a diversidade de premiações revela o quanto também são diversos as experiências, os saberes, as práticas, os prazeres e as finalidades docentes. 0 único elemento que se pode considerar comum entre elas é que todas parecem obstinadas em defender boas práticas docentes, experiências criativas e bem sucedidas. Todas buscam selecionar as práticas de maior êxito no enfrentamento de situações-problemas dos cotidianos dos alunos.

Eis, então, que havia sido identificada uma prática docente em que o/a professor/a não estava institucionalmente/legalmente/formalmente obrigado a cumprir. Competir ou concorrer a esses prêmios, concursos ou olimpíadas dependia exclusivamente de sua vontade ou desejo. Ainda que se possa alegar a existência de uma pressão difusa para "estimular o professor a participar" desse tipo de evento, sobretudo nas premiações que envolvem recompensa financeira, até o momento não foi notificado (ou denunciado) nenhum caso dessa natureza e, se existir, penso que o/a professor/a pode dizer não.

Associada à situação de livre participação dos/as professores/as, busquei uma premiação voltada para a educação básica na qual o Ministério da Educação fosse central, de forma a não perder de vista a relação entre Estado e docência. Então, escolhi como objeto de análise o Prêmio Professores do Brasil/MEC ${ }^{10}$.

O Prêmio Professores do Brasil é uma iniciativa do governo federal e acontece desde 2005, sendo coordenado pela Secretaria de Educação Básica (SEB) e contando com diversas parcerias - institutos, organizações e entidades educativas, geralmente sem fins lucrativos e que atuam com demandas sociais, políticas, científicas e educacionais ${ }^{11}$.

É perceptível a crescente participação dos/as professores/as da educação básica de todo o território brasileiro em tal premiação ${ }^{12}$. A primeira edição teve 1.131 trabalhos inscritos; na 4a

\footnotetext{
${ }^{10}$ Apesar de desejar saber sobre a participação do MEC, não me ocupei em analisar suas possíveis intervenções nessa premiação, até porque não era objetivo da pesquisa analisar o prêmio em si, mas sim os ditos dos professores presentes nos projetos educativos que ganharam a premiação.

${ }^{11} \mathrm{Em}$ geral, esses foram os promotores da premiação: MEC, SEB, Fundação SM, Instituto Votorantim, Abrelivros, Fundação Volkswagen, Undime, CONSED, UNESCO, OEI, CAPES, Fundação Bunge, IPL e Intel.

${ }^{12}$ Também é crescente a participação dos docentes da Educação Básica nas demais premiações.
} 
edição os inscritos somaram 2.100; na 11a edição foram 3.494 projetos $^{13}$.

Analisei apenas os resultados completos e divulgados na internet, que eram, até o ano de 2015, os dados referentes às 5a , 6a e 7ạ edições, isto é, referentes aos editais efetivamente analisados, isto é, dos anos de 2011, 2012 e $2013^{14}$. Essas edições já contemplavam e premiavam toda a educação básica, isto é, desde a educação infantil até o ensino médio. No total, analisei 119 projetos, sem distinção de nível, de modalidade de ensino, nem de área de atuação docente; meu interesse era pela generalidade e não pela especificidade.

Metodologicamente, na medida em que os projetos eram lidos, construí um pequeno protocolo de pesquisa, composto de identificação do projeto, temas principais, temas correlatos, preocupações centrais, preocupações dispersas, desafios, objetivos iniciais, objetivos finais, motivações para a criação dos projetos (motivações que vinham dos/as próprios/as professores/as ou externas a eles/as), práticas, táticas, estratégias utilizadas, oportunidades geradas pelos projetos ou acontecimentos que geraram os projetos, máximas estabelecidas pelos/as professores/as ou diagnósticos por eles realizados, satisfação do/a professor/a, finalidades alcançadas e, por fim, os testemunhos de sucesso ou de limites dos projetos.

A partir das leituras de Foucault sobre ética, percebi que poderia aglutinar os resultados do protocolo acima em quatro grandes elementos: i) prazer docente; ii) assujeitamento moral dos/as professores/as; iii) práticas; iv) finalidades éticas dos/as professores/as.

Na medida em que esses elementos foram se avolumando e se constituindo, percebi que era possível caracterizar - de maneira genérica, é claro - os quatro aspectos da ética desses/as professores/as da seguinte forma: i) o prazer docente pode ser intitulado "nada será destruído"; ii) a docência se sujeita, se rende à defesa de uma "vida útil"; iii) suas práticas se destinam, em geral, a evitar a deserção dos alunos, a construir a boa convivência entre eles ou, ainda, a incentivar a participação da família e/ou da comunidade na vida escolar dos estudantes; iv) por fim, quanto às suas finalidades, a docência parece exigir que essas/es professoras/es sejam atuantes.

\footnotetext{
${ }^{13}$ Disponível em: http://dc.clicrbs.com.br/sc/estilo-de-vida/noticia/2017/12/mec-divulga-vencedores-do-premioprofessores-do-brasil-10098740.html. Acesso em: 26 de junho de 2018.

${ }^{14}$ Atualmente, todas as edições já se encontram disponíveis on-line: http://premioprofessoresdobrasil.mec.gov. br/\#historico.
} 


\section{Ética e experiência em Michel Foucault}

Falar de ética em Foucault é, ao mesmo tempo, tocar em assuntos como experiência, cuidado de si, estética e liberdade, enfim, todos esses temas, digamos, móveis que dizem respeito à atuação do sujeito consigo mesmo e com o outro. São temas que versam mais sobre os usos e as práticas dos sujeitos sobre si e sobre os outros do que sobre as especulações ou imaginações teóricas ou conceituais que os acadêmicos costumam fazer. Por isso, são temas que, como muito bem nos lembra Celso Kraemer (2011), não podem ser tratados de maneira universal ou global; antes, devem ser tomados sempre de modo local e singular, isto é, sempre em "circunstâncias determinadas e condições específicas" (KRAEMER, 2011, p.57).

Essa é a razão pela qual a ética em Foucault é de um tipo muito especial. Ela é a relação do sujeito consigo mesmo, um sujeito inacabado e local e que, como tal, pode se compor e se recompor de diferentes maneiras e possibilidades. Esse tipo de ética exige do sujeito a experiência dele por ele mesmo (experiência de si), ao mesmo tempo em que resulta em um governo sobre o outro.

Assim, a experiência do sujeito por ele mesmo torna-se premissa radical nos últimos estudos de Foucault, o que o fez desenvolver uma série de pesquisas nas quais a ética pessoal se torna uma questão política da maior importância. O eu e o Outro ou o sujeito e o governo se tornam centrais no pensamento foucaultiano.

Especialmente os estudos sobre a sexualidade e sobre o cristianismo permitiram que Foucault nos conferisse importantes conclusões a respeito do que se pode chamar de ética e de experiência, além de nos ajudar a compreender a difícil relação entre subjetividade e verdade.

Pesquisar a experiência do sujeito por ele mesmo significa não idealizar o que ele pode fazer nem denunciar o que ele faz, mas sim compreender como ele se liga a certas verdades, tornando-as suas a ponto de governar a si mesmo e o outro. Assim, Foucault nos convida a considerar mais seriamente a subjetividade forjada no jogo entre o sujeito, o outro e a verdade; ela é a forma política de governar, ao mesmo tempo, a si e os outros; ou seja, o governo do outro é, ao mesmo tempo, um governo de si mesmo e vice-versa.

Em se tratando dos estudos sobre a sexualidade, Foucault verificou, por exemplo, que investigar seus usos e práticas (e não apenas os conceitos, o progresso dos conhecimentos) era 
bem mais potente do que mostrar apenas seu caráter normalizador, o que ele já havia feito na década de 1970. Com isso, poder-se-ia investir na possibilidade de a sexualidade ser também uma forma de acesso à verdade, uma experiência e, por consequência, uma forma de pensamento, isto é, "maneiras de dizer, de fazer, [e] de se conduzir" (FOUCAULT, 2014, p.209).

A fim de pesquisar as práticas por meio das quais os sujeitos se ligam a certas verdades, ou seja, a fim de pesquisar modelos éticos, Foucault (1984), tendo como referência a sexualidade, nos forneceu quatro elementos muito simples, mas realmente potentes, para pensarmos uma genealogia da ética ${ }^{15}$ : substância ética; modo de assujeitamento; atividade formadora de si mesmo; teleologia (finalidade). Tais elementos só foram mais bem explicitados na medida em que o autor localizou as noções mais frequentemente utilizadas no modelo ético da moral sexual grega: aphodisia, chrésis, enkratéia e soprosune ${ }^{16}$. Uma vez localizadas ou identificadas essas noções, Foucault sugere os quatro elementos acima como uma possível dinâmica grega por meio da qual se expressaria a "experiência moral dos prazeres sexuais" (FOUCAULT, 2003a, p.37).

No que diz respeito à substância ética, a pergunta a ser respondida é: "qual é o aspecto ou a parte de mim mesmo ou do meu comportamento que está ligado à conduta moral?" (FOUCAULT, 1984, p.51). Em outras palavras, diante de um desejo, a qual tipo de problematização eu terei que responder? O exemplo utilizado por Foucault foi: "quando um filósofo estava apaixonado por um rapaz, mas não o tocava, seu comportamento era digno. 0 problema era: ele toca ou não o rapaz. Esta é a substância ética ${ }^{17}$ : o ato ligado ao prazer" (FOUCAULT, 1984, p.52). Prazer e desejo estão unidos. Caso o filósofo tocasse no rapaz, talvez fosse julgado indigno, mas não havia culpa, isto é, não se envergonhava do prazer. Também não existiam questões de normalidade ou anormalidade (desvios); ainda que tocasse o rapaz, o filósofo iria fazê-lo de certa maneira e não de qualquer jeito. Em lugar de vergonha, anormalidade ou culpa, havia "atos, gestos, contatos, que proporcionam uma certa forma de prazer" (FOUCAULT, 2003a, p.39). A isso Foucault chamou aphodisia, ou seja, nem culpa nem

\footnotetext{
${ }^{15}$ Uma excelente discussão sobre esses quatro elementos se encontra em Davidson, in: GUTTING, Gary (2016).

${ }^{16}$ Foucault (2003a).

17 Por substância ética, o filósofo não se refere a uma massa inerte e independente dos acontecimentos ou a uma essência do sujeito, e sim aos sistemas de pensamento trabalhados pelo próprio sujeito.
} 
julgamento nem anomalia; atos.

No que tange ao assujeitamento, a pergunta se refere ao "modo pelo qual as pessoas são convidadas ou incitadas a reconhecer suas obrigações morais" (FOUCAULT, 1984, p.53). Ora, as pessoas podem se ver diante de uma lei divina, de uma lei natural, de uma lei científica, de uma exigência política, de uma racionalidade e, em razão disso, cumprirem suas obrigações. No caso dos gregos, eles se viam diante da exigência de uma "existência maravilhosa" (FOUCAULT, 1984, p.55), isto é, defrontavam-se com o problema da boa reputação, que consistia em uma escolha política ou pessoal que permitisse gozar de glória na cidade. Isso quer dizer que, "se querem ter uma boa reputação, se querem ser capazes de governar os outros, têm que fazer isto" (FOUCAULT, 1984, p.55): ter boa reputação. Portanto, governar bem a si mesmo para poder governar o outro.

Ninguém era obrigado a fazer isso, mas quem desejasse trilhar a vida pública deveria ter uma boa reputação, de modo que o assujeitamento aqui é à própria cidade, à polis. Nota-se que não é a lei divina, tampouco uma noção científica que define, de fora, o que é a sexualidade das pessoas, mas há certa obrigação moral com a vida pública. Se alguém desejasse a vida pública, melhor seria que sua sexualidade estivesse à altura do cargo. Esse procedimento sugere uma escolha: se desejo isso, terei que praticar certas coisas; se não desejo essa situação, farei outras coisas da minha vida. Aliás, é em razão dessa possibilidade de escolha que a ética em Foucault é radicalmente diferente de outras maneiras de concebê-la. A tão conhecida noção de ética como "a relação consigo mesmo" (FOUCAULT, 1984, p.54) é, segundo o filósofo, tributária da maneira como os gregos estabeleciam relações com os códigos, com eles mesmos, com as coisas, com o mundo e com os outros.

O terceiro elemento da ética grega é referente à "atividade formadora de si mesmo" (FOUCAULT, 1984, p.54). Tratava-se de exercícios sobre o corpo, das técnicas aplicadas sobre ele, dos combates que os sujeitos travavam sobre si. Tratava-se, portanto, de uma "relação de combate" (FOUCAULT, 2003a, p.62), de uma agonística do sujeito consigo mesmo, de uma necessidade de equipar-se, de preparar-se, a fim de comandar desejos e atos para tornar-se certo tipo de pessoa. Não se tratava de técnicas de purificação, orações ou penitências nem de adaptações a padrões sexuais exteriores, vindos de um conceito científico. Tratava-se, antes, de exercitar sua alma, de escrever, de examinar sua consciência, a fim de "moderar nossos atos [...] 
de usar nosso desejo sexual a fim de obter certos objetivos [...]" (FOUCAULT, 1984, p.53).

Por fim, o quarto elemento, a teleologia (finalidade). No caso da sexualidade grega, era tornar-se um ser temperante; em todo caso, tornar-se senhor de si, ou seja, não ser escravo de ninguém e de nada, nem de si. Não se tratava de buscar a pureza absoluta do ser, a salvação da alma, tampouco de desenvolver uma performance sexual infalível ou de afirmar uma diferença obtusa entre ser homem ou mulher. Tratava-se, antes, de buscar a liberdade, a capacidade de experimentar um cuidado de si mesmo a ponto de superar as próprias fraquezas.

Como se vê, os elementos tomados de Foucault são da maior importância para os estudos éticos. Todavia, é preciso ter em mente que o autor fornece apenas ferramentas para se pensar futuros estudos no campo ético. Além disso, é enganoso atribuir a ele o retorno aos gregos como saída para os problemas atuais ${ }^{18}$. Não! O que se quer é experimentar, no presente, a possibilidade de os indivíduos serem sujeitos morais por eles mesmos.

Em termos docentes, todo cuidado é pouco, sobretudo porque Foucault jamais pesquisou a docência em sentido estrito; tudo que fez foi detalhar práticas sociais, o que, talvez, possa nos interessar na análise da docência como experiência. As práticas são o "Iugar de encadeamento do que se diz e do que se faz, das regras que se impõem e das razões que se dão, dos projetos e das evidências" (FOUCAULT, 2003b, p.338). Nesse caso, as práticas são, enfim, problematizações postas pelos próprios sujeitos professores e impostas aos outros (alunos e comunidades) como matéria sobre a qual se produzem sentidos e que resultam em experiências concretas, a saber: experiências docentes.

Nesse sentido, é claro que foram as contribuições de Foucault relacionadas à questão da ética na sexualidade grega que me instigaram a querer saber qual é ou pode ser o prazer docente. A que ele se submete? Em que práticas ele se apoia? Com qual finalidade?

No referido estudo, tentei localizar esses quatro elementos na docência de maneira bastante arbitrária, pois não dá para equiparar duas experiências tão distintas (sexualidade e docência), ainda que o próprio Foucault tenha experimentado tal dinâmica dos quatro elementos na ética cristã ${ }^{19}$.

\footnotetext{
18 Bernauer e Mahon, In: GUTTING, G. (2016).

${ }^{19}$ Foucault, M (1993).
} 
Seja como for, sustentado nesta dinâmica ética proposta por Foucault e considerando o universo pesquisado, ou seja, professores que decidiram concorrer a um prêmio que valorizasse ou reconhecesse suas experiências docentes, encontrei como, a) substância ética: "não permitiremos que nada seja destruído", daí porque são utilizados temas como meio ambiente, bullying, respeito, cidadania e tecnologia; b) assujeitamento: a uma vida útil, que faça sentido para eles/as e para os alunos; c) práticas: voltadas para evitar a deserção dos alunos, para construir a boa convivência, para a família e para a comunidade; d) finalidade: se tornarem professores/as atuantes, comunitários/as; eles/as não querem ser conhecidos/as como professores/as derrotados/as, depressivas/os, inertes ou coisa parecida.

\section{Da "substancia ética" ou dos prazeres docentes}

A partir dos projetos analisados no âmbito do Prêmio Professores do Brasil, os prazeres docentes podem ser assim traduzidos: estamos prontas para combater toda e qualquer forma de destruição, não deixaremos os alunos destruírem a escola, o patrimônio público, o meio ambiente, nem eles mesmos. De antemão, é necessário dizer que as professoras não anunciam literalmente essa máxima; essa é a minha maneira de interpretá-las.

Chamo atenção também para o fato de que o sujeito da referida máxima está no feminino. Isso se dá porque a participação de homens professores nos projetos analisados é insignificante, portanto não há qualquer razão para falar em professores, no masculino. Daqui em diante, utilizarei a palavra professoras, no feminino, para me referir aos sujeitos da pesquisa.

De onde foi possível retirar essa máxima sobre o prazer docente? Das temáticas dos projetos pesquisados. Elas são diversas, porém, no material pesquisado, havia um número razoável de projetos com temas como violência, bullying, respeito entre as pessoas, vida saudável, meio ambiente, cidadania, tecnologia e assim por diante, e isso foi decisivo para supor que o prazer está em "conservar" ou "preservar" as coisas; não é subverter ou transgredir, mas conservar ou manter ou, como dizem as professoras, zelar pela boa convivência, pelo planeta, pela escola, pela tradição, pelas amizades, pelas relações entre as pessoas etc. 
E de onde vêm essas temáticas? Em parte, elas vêm do $\mathrm{PDE}^{20}$; de outra parte, elas vêm dos diagnósticos produzidos e difundidos pela ONU, UNESCO, MEC, ONG, DCN, Faculdades de Educação e mesmo das políticas públicas educacionais locais (os projetos citam aleatoriamente essas instituições). Os temas são, digamos, de grande apelo social; todos eles remetem à ideia de que se deve fazer um grande acordo mundial pela convivência pacífica e pela paz entre as pessoas e as nações.

Aqui vale a pena abrir um rápido parêntese para dizer que associar a prática docente aos grandes acordos ou problemas mundiais parece ser uma ação relativamente recente. Pelas evidências das práticas ${ }^{21}$, entre o fim do século XIX e meados da segunda metade do século XX, o prazer docente se concentrava em difundir a moral laica entre os alunos; dever-se-ia, assim como pensava Durkheim (2008), combater a crise moral das sociedades modernas por meio de uma educação moral laica - portanto, racionalizada - e não religiosa, por meio de uma organização curricular local que privilegiasse a ocupação de tempos, espaços e conteúdos administrados pelos professores.

Na segunda metade do século XX, esse prazer parece se deslocar para causas globais. Tomando por base as experiências docentes difundidas na Revista Nova Escola a partir de 1986, vê-se a defesa da necessidade de uma suposta compreensão ou diagnóstico das realidades de povos, comunidades, grupos etc. para se praticar a docência. Começa-se a falar em como resolver os problemas do mundo - água, energia, violência, autoritarismos etc. De alguma maneira, a experiência docente - ou algo dela, pelo menos - não mais se restringia ao espaço da escola e ao indivíduo (ao aluno, seu comportamento e sua aprendizagem); tal experiência passa a ser, ao mesmo tempo, global, comunitária e regional ${ }^{22}$.

E é exatamente nessa passagem, isto é, da preocupação moral e individual para um apelo global e humanitário, para problemas globais e locais e suas resoluções, que se vê aprofundar, hoje, a experiência docente. É óbvio que, no passado, também havia preocupações maiores, por exemplo, com a cidade, com a pátria, com a pedagogia, com a humanidade, entre outros, mas

\footnotetext{
${ }^{20}$ Plano de Desenvolvimento da Educação. Criado em 2007, durante o governo Lula, estabelecia o prazo de 15 anos para o desenvolvimento da educação, no que se refere à articulação entre níveis, modalidades e territorialidades, uma vez que a educação brasileira se dá em diferentes modalidades e níveis e também em regiões diferentes e desiguais. ${ }^{21}$ Consultar as experiências docentes contidas na Revista do Ensino, de Minas Gerais, da primeira metade do século XX.

${ }^{22}$ Consultar as experiências docentes contidas na Revista Nova Escola a partir da segunda metade do século XX.
} 
dificilmente havia preocupação com a resolução de crises mundiais. Tudo indica que, desde os anos 1980, o prazer docente passa a atuar pelo menos em duas direções adjuntas: ao mesmo tempo em que age moralmente sobre os indivíduos (questão da aprendizagem com prescrições didáticas, por exemplo), passa a se ocupar também com questões políticas de grande alcance e suas resoluções (meio ambiente, tecnologia, cidadania, direitos humanos etc.).

O aprofundamento desse tipo de docência, digamos, global é realmente evidente nos projetos investigados. Quando se verifica, por exemplo, os motivos que levaram as professoras a construírem os seus projetos, percebe-se que suas motivações estão muito mais ligadas aos discursos dos governos do que aos das ciências pedagógicas; são raros os projetos que dialogam com as questões das ciências da educação. Pode-se inferir que, a partir de discursos globais e humanitários, as professoras governam os alunos para que eles melhorem não apenas o seu comportamento (moral), mas para que também possam ajudar a erguer (e não enfraquecer) as forças de Estado.

Com efeito, o prazer dessas professoras se efetiva na medida em que creem que a sua contribuição para o crescimento da sociedade se encontra paralela às forças do Estado, e não contrárias ou indiferentes. Obviamente, elas sabem que suas contribuições não são decisivas para o Estado, e sim auxiliares, mas nem por isso as consideram fracas ou incipientes; pelo contrário, as consideram impactantes no governo dos alunos e de suas comunidades. A respeito de um projeto sobre o meio ambiente, com boa repercussão em uma escola, diz uma professora: "Porque com estas atividades experimentais estamos lutando para não se fabricar mais sacos plásticos; não se perder as cascas da laranja, ao contrário disto, estamos trabalhando para transformar e assim sendo proteger nosso meio ambiente" 23

Ocorre, contudo, que as contribuições das professoras são tratadas pelo Estado de maneira paradoxal. Os governos incentivam as escolas a governarem os alunos por meio desses discursos, aqui nomeados de globais e humanitários, enquanto que, por meio dos acordos econômicos, destroem os mesmos discursos que incentivaram a proliferar. Na verdade, as contribuições das professoras e/ou da escola não são levadas a sério pelos governos, pois, como

23 Projeto Acordando Lavoisier: na natureza nada se cria nada se perde tudo se transforma (2011). http://premioprofessoresdobrasil.mec.gov.br/15-historico/99-relatos-premiados-ppb-5-edicao-2011. Recuperado em setembro de 2017. 
sabemos, são eles mesmos que colocam a sociedade em perigo. Ora, quem mais entrega o meio ambiente aos interesses econômicos, se não os governos?

De maneira que sou obrigado a concluir que, por um lado, as professoras, por quererem ajudar a governar, estabelecem um vínculo gratuito com o Estado ou com os governos; por outro lado - e por isso mesmo -, estabelecem um vínculo solidário e endereçado aos alunos e comunidades, oferecendo-Ihes, entre outras coisas, ajuda para que não destruam a sociedade, o mundo e a eles próprios.

Mas isso não é tudo, ou seja, as professoras não agem assim porque se sentem ilusoriamente sustentadas pelo Estado. Mais do que isso, elas assim procedem porque o diagnóstico político-pedagógico que rege sua forma de pensar parece informá-las que, em geral, os alunos, por viverem em lugares violentos ou perigosos e sendo, portanto, vulneráveis e desinteressados pelos estudos, são muito carentes de atenção e de valorização de suas potencialidades ${ }^{24}$, o que faz com que elas se sintam convocadas a atuar sobre eles a fim de ajudálos. Tal diagnóstico é tão potente que, na visão das professoras, quando o aluno compreende as razões pelas quais elas se dedicam a eles, tudo se altera radicalmente; eles se modificam para melhor ao término dos projetos.

Se os alunos são caracterizados por esses atributos, as temáticas que visam a discutir a preservação do meio ambiente, o respeito, a cidadania, a tecnologia, a alimentação, o bullying, o empreendedorismo a discriminação, entre outras, estão perfeitamente justificadas e, de quebra, justifica-se também a quase ausência de temas como gênero, sexualidade, racismo, política, religião, bastante raros nos projetos analisados. Vê-se aí uma escolha clara por certas temáticas em detrimento de outras. Porém, mais do que isso, vê-se mesmo uma estratégia ética e política de governo pedagógico que mistura atuação sobre os alunos pobres e forças de Estado, isto é, o que está em jogo nesse tipo de docência é a imbricação entre pobreza, docência,

\footnotetext{
${ }^{24}$ Consultar, pelo menos, os seguintes projetos: Bullying - Respeite as diferenças! (2011) - Disponível em: http://premioprofessoresdobrasil.mec.gov.br/15-historico/99-relatos-premiados-ppb-5-edicao-2011; Educação, empreendedorismo e sustentabilidade (2011) (idem); Projeto Palavras e canções (2011) (idem); Projeto ensinando com Arte (2012) - Disponível em: http://premioprofessoresdobrasil.mec.gov.br/15-historico/100-relatospremiados-ppb-6-edicao-2012; Hablar espanol es exquisito (2012) (idem); Literar é só começar (2013) - Disponível em:http://premioprofessoresdobrasil.mec.gov.br/15-historico/101-relatos-premiados-ppb-7-edicao-2013; Transformando a escola... Respirando Arte (2013) (idem); Brinquedoteca: Oxente, aqui eu aprendo brincando (2013) (idem). Todos os links foram recuperados em setembro de 2017.
} 
educação e Estado.

Trata-se de uma estratégia ética na medida em que as professoras acreditam seriamente no que defendem; trata-se de uma estratégia política porque elas pretendem multiplicar os efeitos desses projetos pela cidade, pretendem a aproximação com lideranças comunitárias, igrejas, ONG, associações, rádios, faculdades locais, pequenos comércios, entre outros.

Em uma perspectiva foucaultiana, a ética grega compartilhava com a política o mesmo problema filosófico, isto é, o de como governar a si mesmo e o outro; ambas tratavam, pois, de uma questão de governo, o que implicava a relação do sujeito com a cidade/política. Se havia, de fato, essa estreita relação entre ética e política, podemos dizer, com Castro (2009), que a ética grega dos prazeres "constitui uma político-estética, isto é, uma escolha livre na qual estão em jogo o governo de si e dos outros" (p.156). O prazer docente, na pesquisa em questão, parece ser também um jogo político, uma constituição estético-política, pela qual os docentes exercem - ou desejam exercer - um governo de si e das populações estudantis.

Obviamente, toda a análise aqui sugerida é precária demais para concluir o que é ou como funciona o prazer docente dessas professoras, mas gostaria de argumentar que, em termos políticos mais amplos, tal prazer, da forma como foi exposto aqui, parece achar uma correspondência significativa em um discurso que pode ser nomeado "discurso da paz".

Ocorre que, entre as professoras, não há qualquer definição do que venha a ser o discurso da paz; ele aparece simplesmente como um valor que combate a violência. Assim, me pergunto: seria o prazer docente, este de impedir que a sociedade seja destruída, um outro nome da paz?

Patrícia Birman (2012), ao analisar a questão da violência no Rio de janeiro, indica que a paz, para além de uma questão religiosa, se transformou em um acordo entre diferentes instâncias políticas contra uma violência cuja origem tem sido ignorada de propósito. Ninguém se pergunta como a violência é produzida; a paz é simplesmente tomada como a solução para os problemas da violência. Um exército de bem-intencionados aparece para conter a violência: religiosos, assistentes sociais, ONG, educadores, policiais e tantos outros. A autora dá a entender que a violência e o crime se tornaram, hoje, dois elementos indispensáveis no cálculo do Estado para fins de governo de populações. Por meio desse cálculo, cria-se no imaginário social a ideia de que onde há violência e crime, há pobres.

Ora, será que é por isso que as professoras sugerem que os projetos ajudariam a lidar Periódico Horizontes - USF - Itatiba, SP - Brasil - e019024 
com o universo da violência e do desinteresse dos alunos? Essa seria a razão pela qual o alvo preferido das professoras são os alunos que habitam as regiões perigosas das cidades? Na esteira das questões de Birman (2012), pergunto-me também: isso justificaria o fato de se falar mais em projetos do que em aulas? Seria porque a aula implica apenas uma simulação da vida, enquanto o projeto implicaria em uma ação efetiva de intervenção social? O projeto implicaria parcerias mais efetivas com o Estado, universidades, empresas, comércios locais, associações de bairro, rádios comunitárias, ONG, projetos sociais, bancos etc.? Ou simplesmente se trata de combater um contexto inconteste de violência urbana?

\section{Das sujeições docentes}

Em Foucault, a sujeição "é o modo pelo qual as pessoas são convidadas ou incitadas a reconhecer suas obrigações morais" (FOUCAULT, 1984, p.53). Isso significa saber os meios de que os indivíduos dispõem para obter o prazer, isto é, o tipo de sujeição que ele faz ou a que ele se submete para obter o prazer. Na docência aqui investigada, uma sujeição se apresenta significativamente: a disposição de ser útil à sociedade.

Mas o que é uma educação útil à sociedade? No fim do século XIX e primeira metade do século XX, dizia-se, no Brasil, que uma educação útil era aquela que auxiliava na construção da nação e na modernização do país a partir das ciências, da moral laica e de suas relações com as novas formas produtivas ${ }^{25}$. A experiência educativa da época não media esforços para atingir essa finalidade ${ }^{26}$. Contudo, tal docência não cumpria essa utilidade sem separar as escolas para as elites das escolas para os trabalhadores: para uns, os conteúdos científicos; para outros, saberes instrumentais e moralizadores de comportamentos. A docência da educação primária tinha exatamente essa utilidade, isto é, transformar os filhos dos pobres em trabalhadores moralizados e dotados de noções científicas básicas a fim de atender as novas demandas de mercado e de comportamento.

Na Europa, conforme Varela e Alvarez-Uria (1992), na primeira metade do século XIX, a

\footnotetext{
25 SOUZA (2000).

${ }^{26}$ Consultar GIL et al (2012).
}

Periódico Horizontes - USF - Itatiba, SP - Brasil - e019024 
educação útil também não se deu sem a existência de uma escola específica para as classes populares, para que os pobres se tornassem produtivos. Segundo os autores, pelo menos inicialmente, tal escola, como já era de se imaginar, se colocou em franca oposição aos valores cultivados pelos populares, o que resultou em uma escolarização que, mais do que ensinar os conteúdos úteis, impôs aos pobres "hábitos de limpeza, regularidade, compostura, obediência, diligência, respeito à autoridade, amor ao trabalho e espírito de poupança" (VARELA; ALVAREZURIA, 1992, p.82).

Hoje, é claro, gostaria de acreditar não se tratar mais do tipo de educação requerida anteriormente. Porém, pergunto-me: em que medida a preocupação com o pobre permaneceu na docência brasileira? E com qual conteúdo?

Nos projetos das professoras - e somente aí, pois não possuo condições de verificar essa questão em termos mais amplos e documentais -, a palavra "pobre" desaparece e, em seu lugar, a palavra "cidadão" é evocada a perder de vista. Contudo, não há qualquer reflexão mais elaborada sobre essa noção; as professoras apenas dão a entender que o cidadão é ou deve ser um indivíduo ativo, que participa ou deve participar, junto com os demais, da resolução dos problemas vividos na escola ou na comunidade. Em outras palavras, de um ponto de vista prático, a preocupação das professoras é como tornar o pobre - ou melhor, o cidadão - um sujeito útil, quer dizer, ativo e colaborador diante dos problemas sociais. Essa é a razão pela qual as professoras defendem e se ocupam com os temas globalizantes, uma vez que esses as lançam para as questões mundiais e suas relações locais, e com os temas humanitários, porque esses fazem forte apelo para que os alunos se ajudem mutuamente.

Sem oferecer grandes explicações sobre essa cidadania ou sobre como ser útil à sociedade, as professoras simplesmente agem, ao que tudo indica, em três direções, que denominarei aqui de princípios: princípio do aleatório, princípio do comunitário e princípio da criação ou da inovação.

O princípio do aleatório se dá por constantes e variadas intervenções educativas sobre as populações pobres. As professoras parecem compreender que, para os jovens que habitam as regiões violentas, os desinteressados da escola ou os apáticos diante da aprendizagem (as três 
justificativas mais utilizadas pelos projetos) $)^{27}$, não se deve disponibilizar apenas um único objetivo e tampouco restringir os projetos ao seu caráter aulístico - sala de aula. Pelo contrário, quanto mais desdobramentos e apelo social os projetos forem capazes de empreender, melhor.

Assim, o princípio do aleatório, como o próprio nome sugere, melhor se define pela incerteza das práticas, na medida em que as professoras não sabem ao certo quais serão os resultados dos seus projetos. O que importa é dispor aos alunos a maior quantidade possível de atividades ou de tarefas, digamos, socioeducativas, com vistas à melhoria de suas vidas ou, talvez, ao seu engajamento em alguma atividade social. Pelo princípio do aleatório se espera que, em algum momento, os alunos possam modificar suas vidas e a vida dos outros. Tal princípio foi localizado na medida em que nenhum dos projetos estudados se restringiu aos objetivos proclamados; seus objetivos se multiplicavam, se desdobravam em várias outras frentes de trabalho.

Em outras palavras, o princípio do aleatório tenta demover os alunos de seu "quase destino" e se transforma em uma possível saída para a atual condição pessoal e social deles, caracterizada, como já foi dito, pela apatia, pela pobreza, pela violência, pelo desinteresse. Talvez, esse princípio sirva também para alterar a condição docente das próprias professoras, inquietas por mudanças. Em nome desse princípio, elas garantem que os alunos modificaram suas vidas e relatam que se sentem realmente felizes com as transformações subjetivas e objetivas alcançadas por meio dos projetos.

Quanto ao princípio do comunitário, pode-se dizer que não há praticamente nenhum projeto que não desejasse "atingir" a comunidade. Tal princípio caminha em duas direções: uma que faz referência à família, isto é, como "trazer a família" para a escola, para vida dos alunos; outra, não tão evidente, que caminha na direção de forjar uma dupla realidade educacional: construir outra noção de escola e mudar os conteúdos escolares.

Nessa nova realidade educacional, a comunidade (e não apenas a sala de aula) seria central e a escola não seria uma instituição concêntrica, mas sim excêntrica, isto é, interessada por questões para além dos seus muros. Quanto aos conteúdos escolares, eles poderiam se

27 Projeto Do porquinho ao leão: para onde vai o meu tostão (2011). Disponível em: http://premioprofessoresdobrasil.mec.gov.br/15-historico/99-relatos-premiados-ppb-5-edicao-2011. Recuperado em setembro de 2017. 
materializar em forma de projetos, porém projetos socioeducativos; mais do que ensinar as coisas da escola, dever-se-ia, por meio desses projetos, auxiliar os alunos a se engajarem em alguma causa social, política, científica, produtiva, subjetiva, militante etc ${ }^{28}$.

Por fim, o último princípio, o da criação ou da inovação. Nesse caso, as professoras se preocupam em atualizar os alunos em três aspectos: as novidades tecnológicas, ambientais e relacionais. As novidades tecnológicas dizem respeito ao uso das mídias para fins educativos, por meio de blogs, filmagens e grupos virtuais de discussão, por exemplo. As novidades ambientais dizem respeito a tudo que poderíamos colocar sob o nome de preservação/promoção, como saúde, limpeza urbana, drogas etc. As novidades relacionais visam aos cuidados com o outro, se efetivando a partir dos temas do respeito, bullying, discriminação e cidadania.

As três novidades estão sob a rubrica da intervenção, isto é, elas só entram nos projetos com a condição de que os alunos produzam algum resultado concreto, como visitar lagoas e nascentes de rios, fazer maquetes sobre o meio ambiente, ajudar pessoas com deficiência, visitar idosos, filmar as atividades dos colegas, abrir um blog para postar notícias sobre os projetos etc. Não se trata apenas de excursões escolares, mas da constatação de problemas sociais reais para fins de resolução, de intervenção.

Em resumo, a sujeição docente se dá por meio de uma utilidade educativa que visa a constatar e pensar soluções para problemas sociais. Não é mais apenas uma questão de fazer os pobres se tornarem trabalhadores, embora essa finalidade não pareça estar totalmente descartada. Tal sujeição se dá na medida em que parece existir uma nova visão da pobreza e dos pobres, em especial aquela que jamais identifica o pobre com a pobreza, que devolve a ele a possibilidade de ele mesmo se livrar dela. Receio que todo esse processo, digamos, utilitário da docência só seja realizado em razão dessa certa visão da pobreza. E isso acende uma questão: para os pobres, basta uma mobilização moral para que se identifiquem e ajudem a resolver as questões sociais das quais eles são mais vítimas do que causadores?

Não foi possível concluir nada nessa direção, mas me perguntei qual, de fato, poderia ser

\footnotetext{
${ }^{28}$ Vários são os projetos que podem ser citados para exemplificar essa assertiva, se não todos. Um, em especial, ilustra bem a discussão: Educação para o trânsito na escola - uma questão de Direitos Humanos (2011). Disponível em: http://premioprofessoresdobrasil.mec.gov.br/15-historico/99-relatos-premiados-ppb-5-edicao-2011. Recuperado em setembro de 2017
} 
o efeito desses três princípios da utilidade educativa (aleatório, comunitário e criativo) tão requeridos pelas professoras. Imagino, no entanto, que o efeito mais relevante vai em uma direção bastante inusitada, que não guarda nenhuma relação com que se dizia a pouco: a intensa relação de amizade que as professoras dizem estabelecer com esses alunos, pobres ou não, por meio de seus projetos.

Porém, essa discussão merece maior investimento teórico e prático, o que não fui capaz de fazer para este artigo. Entretanto, dadas as pistas que as professoras deixaram sobre o problema da amizade, presumo - é uma aposta - que o prazer docente dessas professoras, para além de ser generoso e humano, circunscreve-se na tentativa de fazer das amizades escolares a aposta da felicidade (a salvação) dos alunos (pobres ou não) e, quem sabe, do mundo.

\section{Das práticas das professoras}

Quanto às práticas, não foi possível localizar práticas de si do tipo exame de consciência, escrita de si ou exercícios espirituais. Em seu lugar, encontrei práticas destinadas ao outro, nesse caso, práticas docentes destinadas aos alunos. Nessa direção, localizei pelo menos três práticas orbitando os prazeres docentes: as que visavam a evitar a deserção dos alunos; as que visavam a obter a obediência deles; por fim, as que visavam ao conhecimento escolar útil.

Se o prazer docente aqui estudado envolve a não destruição do mundo, o cultivo de uma vida útil e o estabelecimento da felicidade entre as pessoas, se a escola é um bom lugar para que essas coisas aconteçam, lutar para que os alunos queiram as coisas da escola é, obviamente, uma das primeiras e permanentes atitudes praticadas ao longo do desenvolvimento dos projetos aqui pesquisados.

Os projetos não dizem literalmente, mas dão a entender que, apesar de os alunos gostarem das escolas, três problemas são percebidos na relação deles com ela. O primeiro diz respeito a certo contexto social amplo marcado pela violência, pobreza e pela ausência das famílias, que resulta no desinteresse dos alunos pela escola. O segundo problema aponta para as condições estruturais das escolas, isto é, faltam-Ihes boas condições físicas e materiais para ofertar aos alunos. E o terceiro diz respeito à necessidade de certa austeridade sobre os corpos dos alunos para que, talvez, eles aprendam os conteúdos escolares. Esse diagnóstico revela três 
grandes conhecidos entraves na prática docente: apatia escolar, infraestrutura física e questões didáticas. Trata-se de problemas estruturais na educação brasileira, cuja resolução as professoras entendem não depender totalmente delas.

Em compensação, elas afirmam que fazem a sua parte. Por exemplo: a fim de evitar a deserção, promovem conversas, aconselhamentos, estabelecem amizades, incentivam os alunos a estudar, dão atenção àqueles que mais precisam, oferecem ajuda para os mais desanimados etc. Porém, só isso não basta; são necessárias outras práticas a fim de obter a obediência deles.

O primeiro passo é abrandar a aspereza dos conteúdos escolares, o que é feito com o uso de práticas lúdicas e tecnológicas para incentivar a intimidade dos alunos com os conteúdos científicos. A depender de cada escola, tais práticas se dão por meio de música, dança, poesia, narração de histórias, teatro, oficinas, confecção de maquetes, brincadeiras, gincanas, caminhadas, criação de blogs, visita a lugares da comunidade ou da cidade, uso das salas de informática, dos laboratórios de ciências e da quadra de esportes, entre outros.

Isoladamente, essas atitudes até produzem algum efeito, mas servem melhor aos propósitos das professoras quando se encaixam na dinâmica geral dos projetos. No interior dos projetos, elas parecem realmente capturar a atenção dos alunos e suprir relativamente os já citados problemas estruturais e sociais da escola brasileira.

Não obstante - e essa é a segunda prática -, as professoras atuam na direção de zelar pelo bom comportamento dos alunos. Por meio das atividades lúdicas, aconselhamento e uso das tecnológicas, elas indicam aos alunos os bons modos de relacionamento entre as pessoas, como o compartilhamento dos espaços, tempos e objetos, a solidariedade e o respeito. Dizem que as crianças precisam ser educadas desde cedo e ficam indignadas quando veem os alunos mais velhos ignorando esses zelos pela boa convivência; trata-se de uma política em prol do coletivo.

Por fim, a terceira prática, isto é, aquela que visa ao conhecimento escolar útil. No fundo, as professoras gostariam de realizar essa prática de forma direta e tranquila, mas não é o que acontece. Elas só conseguem efetivá-la com o forte apoio das outras duas práticas aqui apresentadas. Do ponto de vista das professoras, o conhecimento escolar é o que realmente importa, mas é o que elas menos conseguem realizar a contento. Aprender matemática, português, história, ciências, a ler, a escrever e a desenvolver o raciocínio são coisas que só se dão por meio de muito esforço localizado. Interessante é que as professoras não lutam, necessariamente, pelo Periódico Horizontes - USF - Itatiba, SP - Brasil - e019024 
ensino formal dos conteúdos, mas para oferecer a contextualização necessária a certos aspectos desses conteúdos, o que tentam fazer por meio dos projetos escolares ${ }^{29}$.

Pelos projetos analisados, ouso inferir que as três práticas aqui apresentadas - a deserção (evitar o abandono), a obediência (criar a boa convivência) e a aquisição do conhecimento escolar útil - compõem um possível quadro atual de certo trabalho docente em ação. Longe estou de fazer um detalhamento dessas práticas, pois há um conjunto de elementos que merecem estudos mais aprofundados. Por exemplo: em termos de ação docente, as professoras convidam os alunos a ler, escrever, falar, fazer, criar, agir, ver etc. Porém, o que cada uma dessas ações pode significar no conjunto geral de uma experiência docente nos dias de hoje? Elas respondem a qual urgência da política educacional brasileira e mundial? Vale recordar que, na passagem para o século XX, práticas como ler, escrever e contar eram a forma pela qual o Estado introduzia a ciência na vida prática da população pobre a fim de modernizá-la. A que corresponderia, hoje, práticas como, ler, escrever, falar, fazer, criar, agir, ver etc.?

Seja como for, observa-se, por meio das três práticas, o tipo de cálculo praticado pelas professoras sobre os alunos. Tal cálculo atua na direção de reter os alunos, docilizá-los e ensinarIhes os conteúdos escolares atuais. Retêm os alunos porque há, de fato, uma recusa deles à escola da maneira como ela se apresenta; os docilizam porque é necessário dispor o corpo dos alunos para algum tipo de produção; ensinam-Ihes porque, afinal, essa é a tarefa da escola ainda que sejam outros conteúdos (os problemas globais) e de outra maneira (a partir de projetos locais).

\section{Das finalidades dos prazeres docentes}

Conforme Foucault nos indicou, em geral, a finalidade da prática ética, nos gregos, indicava o alvo final que se desejava atingir no conjunto geral de certa problematização ética. $\mathrm{Na}$ sexualidade grega, tratava-se de cumprir a sophrosune, isto é, a temperança diante da prática

\footnotetext{
${ }^{29}$ Consultar o projeto Brincadeiras de criança e as possibilidades de integração com a família (2011). Consultar também Educação para o trânsito na escola - uma questão de direitos humanos (2011). Ambos os links estão disponíveis em: http://premioprofessoresdobrasil.mec.gov.br/15-historico/99-relatos-premiados-ppb-5-edicao2011. Recuperados em setembro de 2017.
} 
sexual (FOUCAULT, 2003a). No mundo cristão, tratava-se da salvação da alma (FOUCAULT, 1993). No caso da experiência dessas professoras, parece que há um desejo de alcançar um status de pessoa ativa ou, talvez, de mulher atuante, mais especificamente, professoras que atuam no sentido de transformar a vida dos alunos.

É difícil dizer com precisão qual é a finalidade última dessa experiência docente, todavia há um indicativo importante a se considerar: o impacto dos projetos nas vidas das professoras. Minha aposta é que elas se sentem realmente felizes por estarem ocupadas com uma ação educativa que, não raras vezes, transcende o espaço escolar. A transformação do aluno para além da escola parece, então, ser alguma coisa que as modifica profundamente.

A vontade de atuar junto a alunos, famílias e/ou comunidades ilustra uma finalidade inconteste, para elas. Transformar a vida dos outros por meio de uma atuação endereçada é, sem sombra de dúvidas, o ponto alto de sua caminhada. Diz uma professora em relação a uma atuação que teve com os alunos e a comunidade: "[isso me faz] sentir esse orgulho novamente de ser 'professora' e o sabor de sempre ir além!"30.

Palavras e expressões como "orgulho", "novamente" e "ir além" representam bem a satisfação das professoras com o tipo de atuação que realizam, embora, é preciso destacar, pareçam incomodar alguns. Segundo elas, seus colegas nas escolas zombam e julgam suas ações, perguntando se elas querem ser as heroínas da docência ${ }^{31}$. Como resposta, uma professora ironiza e afirma sua ética:

[...] como aquela velha história do menino que jogava as estrelas de volta para o mar. 'Se conseguimos fazer a diferença para a diminuição de uma garrafa pet no leito do Rio, se conseguimos fazer a diferença para uma única família, uma única vida, já valeu todo empenho, esforço e dedicação e nós estamos fazendo a nossa parte...'. São esses desafios que nos fazem continuar... ${ }^{32}$

30 Projeto Somos um pouco de todas as nossas lembranças juntas...(2013). Disponível em:http://premioprofessoresdobrasil.mec.gov.br/15-historico/101-relatos-premiados-ppb-7-edicao-2013. Recuperado em setembro de 2017.

31 Projeto Família para compartilhar, escola para aprender, juntas para viver! (2013). Disponível em: http://premioprofessoresdobrasil.mec.gov.br/15-historico/101-relatos-premiados-ppb-7-edicao-2013.

Recuperado em setembro de 2017. Ver também: Pequenos artistas (2011). Disponível em: http://premioprofessoresdobrasil.mec.gov.br/15-historico/99-relatos-premiados-ppb-5-edicao-2011. Recuperado em setembro de 2017.

32 Projeto Educação, empreendedorismo e sustentabilidade: pensando no amanhã (2011). Disponível em http://premioprofessoresdobrasil.mec.gov.br/15-historico/99-relatos-premiados-ppb-5-edicao-2011. Recuperado em setembro de 2017. 
Às vezes elas se queixam, dizendo que os/as professores/as são resistentes às mudanças ${ }^{33}$, dando a entender que as/os demais docentes deveriam não apenas dar aulas, mas também atuar junto aos alunos e suas famílias. A satisfação é grande quando conseguem converter outros/as professores/as para esse tipo de atuação. Confessa uma professora "[que ficou] satisfeita [...] Senti que teria o apoio de todos e isso era muito importante para o que eu almejava, porque sem o auxílio de toda a comunidade escolar esse projeto estaria impossibilitado de acontecer" ${ }^{34}$.

Mas é necessário verificar em que direção a atuação dessas professoras caminha. Pareceme que há duas: uma no sentido da "transformação da vida dos alunos", que justifica o trabalho com os projetos e com os conteúdos escolares úteis; outra que vai no sentido de "envolver a família dos alunos com a escola", razão pela qual as professoras falam incessantemente das comunidades.

Enquanto a "transformação da vida" se ocupa em construir sentidos para que os alunos não abandonem a escola e até, eventualmente, concluam sua escolarização, "envolver as famílias" significa não apenas requerer o apoio delas para os alunos, mas convocar a sociedade para se responsabilizar pelo mundo (meio ambiente, cidadania, respeito, alimentação saudável etc.). Essas duas direções só parecem viáveis por meio dos projetos educativos; são eles que permitem a passagem e a relação entre a transformação da vida e a participação da família e/ou das comunidades. Vale dizer que essas professoras só se consideram ativas ou atuantes na medida em que agem nessas duas direções (transformar vidas/convocar comunidades). No caso desse estudo, pode-se arriscar a dizer que não há atuação docente sem essa conexão.

Além disso, é importante apostar que cada uma dessas direções parece ter uma relação, se não absoluta, pelo menos de acentuada dependência, com a outra. A questão da transformação da vida dos alunos, por exemplo, se deve à vontade de querer que eles fiquem na escola e de incutir-lhes novas formas de vida, sendo necessário mudar a vida das famílias e das comunidades para que elas também possam modificar suas próprias vidas.

\footnotetext{
33 Projeto Recursos da Informática X Escola Especial: um Elo para o Desenvolvimento Cognitivo de Deficientes Mentais (2011). Disponível em http://premioprofessoresdobrasil.mec.gov.br/15-historico/99-relatos-premiadosppb-5-edicao-2011. Recuperado em setembro de 2017.

34 Projeto Memórias (2011). Disponível em: http://premioprofessoresdobrasil.mec.gov.br/15-historico/99-relatospremiados-ppb-5-edicao-2011. Recuperado em setembro de 2017.
}

Periódico Horizontes - USF - Itatiba, SP - Brasil - e019024 
Os projetos das professoras funcionam como uma espécie de micropolítica educativa, produzindo dois paradoxos: um que diz respeito aos conhecimentos destinados aos alunos e outro que toca na questão da formação de professores. O paradoxo sobre os conhecimentos a serem ofertados a esses alunos problematiza se é realmente necessária a soberba dos conhecimentos escolares, se não seria o caso de apresentar-Ihes os conteúdos mais aplicáveis possíveis. O segundo paradoxo parece encurralar a formação de professores: ou ela cede de vez às ações dos governos, isto é, passa a formar professores práticos, ou passa a auxiliar os professores a conceber e praticar projetos educativos de intervenção ética (e não de intervenção moral).

Em resumo, o que este artigo quis discutir, em primeiro lugar, é o fato de a docência ser um espaço ético-político, na medida em que as/os professoras/os praticam aquilo que acreditam e que não será fácil demovê-las/os do lugar em que se encontram. Elas ou eles não são apenas subordinados às leis pedagógicas; também acreditam em suas próprias leis de ensino. Além disso, não dispensam reflexões pedagógicas, econômicas ou políticas, mas tampouco reduzem o fenômeno educativo a uma delas.

Em segundo lugar, quis afirmar que a docência é múltipla e heterogênea e que a pesquisa realizada não reflete, de maneira alguma, a totalidade das práticas educativas. Ela traz apenas um pequeno retrato, certo movimento daquilo que algumas professoras parecem praticar atualmente. Em razão disso, provavelmente, outras pesquisas irão localizar outras práticas, que podem ou não se aproximar das que foram aqui relatadas.

Quis dizer também que deve existir um conjunto heterogêneo de agrupamentos docentes atuando dentro das escolas. Quando digo grupos docentes, quero dizer pensamentos e ações que ganham corporeidade por meios dos professores, ou seja, são formas de vida, de existências que, inevitavelmente, vivem, trabalham e falam, a fim de ocupar um lugar na docência e no mundo.

Por fim, este trabalho quis afirmar o caráter histórico da docência, pois ela não é uma experiência transcultural que atravessaria os tempos e a humanidade. Não! A docência, mais uma vez, se mostrou histórica e politicamente localizada. A maior pista de sua historicidade é o fato de as professoras pesquisadas estarem forjando, por meio dos projetos socioeducativos, outra docência: global, local, humanista e de resolução de problemas sociais. 


\section{Referências}

BERNAUER, J.; MAHON, M. In: GUTTING, G. Foucault. Trad. André Oídes. São Paulo: Ideias \& Letras, 2016, p.189-218.

BICCAS, M. S. Nossos Concursos e A Voz da Prática: a Revista do Ensino como estratégias de formação de professores em Minas Gerais (1925-1930). Uberlândia: Editora da Universidade Federal de Uberlândia/Cadernos de História da Educação, n.4, jan/dez, 2005.

BIRMAN, P.Cruzadas pela paz: práticas religiosas e projetos seculares relacionados à questão da violência no Rio de Janeiro. Religião e Sociedade, Rio de Janeiro, v. 32, n.1, p.209-226, 2012.

CASTRO. E. Vocabulário de Foucault - Um percurso pelos seus temas, conceitos e autores. Trad. Ingrid Müler Xavier. Belo Horizonte: Autêntica, 2009.

DAVIDSON, A. Ética como ascese: Foucault, a história da ética e o pensamento antigo. In: GUTTING, G. Foucault. Trad. André Oídes. São Paulo: Ideias \& Letras, 2016, p.159-187.

DURKHEIM, E. A educação moral. Trad. Raquel Weiss. Petrópolis, RJ: Editora Vozes, 2008.

FOUCAULT, M. O Dossier: últimas entrevistas. In: ESCOBAR, C. H. Rio de Janeiro: Taurus Editora, 1984.

FOUCAULT, M. Verdade e subjectividade (HowisonLectures). Revista de Comunicação e Linguagem, Lisboa: Edições Cosmos, n.19, p.203-223, 1993.

FOUCAULT, M. História da sexualidade - o uso dos prazeres. Trad. Maria Thereza da C. Albuquerquer. Rio de Janeiro: Edições Graal, 2003a.

FOUCAULT, M. Mesa-Redonda em 20 de maio de 1978. In: MOTTA, M. B. Ditos e Escritos IV Foucault: estratégia, poder-saber. Trad. Vera Lucia A. Ribeiro. Rio de Janeiro: Forense Universitária, 2003b, p.335-351.

FOUCAULT, M. Prefácio à História da Sexualidade. In: MOTTA, M. B. Ditos e Escritos IXFoucault: genealogia da ética, subjetividade e sexualidade. Trad. Abner Chiquieri. Rio de Janeiro: Forense Universitária, 2014, p.207-213.

GIL, N.et al. Moderno, modernidade e modernização: a educação nos projetos de Brasil séculos XIX e XX. Belo Horizonte: Mazza Edições, 2012.

JOSSO, M. Experiências de vida e formação. Trad. José Cláudino e Júlia Ferreira. São Paulo: Cortez, 2004.

KRAEMER, C. Crítica, liberdade, arte e transversalidade em Michel Foucault. In: RESENDE, H. 
Michel Foucault: transversais entre educação, filosofia e história. Belo Horizonte: Autêntica, 2011, p.35-64.

LARROSA, J. Notas sobre a experiência e o saber de experiência. Revista Brasileira de Educação. Rio de Janeiro, n.19, p.20-28, 2002.

LARROSA, J. (Org.). Elogio da escola. Belo Horizonte: Autêntica, 2017.

LÜDKE, M. O professor, seu saber e sua pesquisa. Educação \& Sociedade. Campinas, ano XXII, n.74, p.77-96, 2001.

MARTINS, F; NETTO, M.; KOHAN, W. Encontrar escola: o ato educativo e a experiência da pesquisa em educação. Rio de Janeiro: Lamparina/FAPERJ, 2014.

MENIN, M. S. S. Valores na escola. Educação e Pesquisa, São Paulo, v. 28, n.1, p.91-100, jan./jun.2002.

MONTEIRO, A. M. F. C. Professores: entre saberes e práticas. Educação \& Sociedade, Campinas, ano XXII, n.74, p.121-142, 2001.

OLIVEIRA, R. J. Ética na escola: (re)acendendo uma polêmica. Educação \& Sociedade, Campinas, v. 22, n.76, out., p.212-231, 2001.

PAQUAY, L. et al. Formando professores profissionais - Quais estratégias? Quais competências? Porto Alegre: Artmed Editora, 2001.

SOUZA, R. F. Inovação educacional no século XIX: a construção do currículo da escola primária no Brasil. Cadernos Cedes, ano XX, n.51, p.09-28, novembro/2000.

TARDIF, M. Saberes docentes e formação de profissional. Trad. Francisco Pereira. Petrópolis: Vozes, 2002.

VARELA, J.; ALVAREZ-URIA, F. A maquinaria escolar. Teoria e Educação, Porto Alegre:

Pannonica, n.6, p.68-95, 1992.

Recebido em fevereiro de 2019.

Aprovado em abril de 2019. 